\title{
Knowledge of peri-menarcheal changes and a comparative analysis of the age at menarche among young adolescent school girls in urban and rural Cameroon
}

Atem Bethel Ajong ${ }^{1,2^{*}}$ (D) Nkengazem Nerry Tankala ${ }^{3}$, Martin Ndinakie Yakum ${ }^{4}$, Ikei Solange Azenoi ${ }^{5}$ and Bruno Kenfack ${ }^{6,7}$

\begin{abstract}
Background: Menarche is an expected event that occurs during the development of every normal young girl. We designed this study to evaluate the knowledge of young school girls on puberty, menarche, and menstruation, and to update data on the age at menarche in a rural and urban setting in Cameroon.

Methods: We conducted a cross-sectional survey from February to March 2017, targeting female students aged 9 to 16 years in Yaoundé (urban) and Bamougoum (rural). Participants were included using a randomised cluster sampling and data collected using an auto-administrable questionnaire. Student t-test or the Kruskal-Wallis test was used to compare means, and the odds ratio used as the measure of association between age at menarche and selected covariates.

Results: 1157 participants were included in the study; 49.3\% from an urban setting and 50.7\% from a rural setting. Regarding the knowledge of our participants on puberty, menarche, and menstruation, $67.20 \%$ of rural participants had good knowledge, whereas only $46.00 \%$ had good knowledge in the urban setting. Mean age at menarche was $12.76 \pm 1.33$ years, with the mean age at menarche in the urban setting of $12.48 \pm 1.12$ years and the rural setting of $13.03 \pm 1.46$ years. Mean age at menarche was significantly lower in participants aged below 14 years ( $p$-value $=$ 0.000 ), those with both parents alive $(p$-value $=0.0461)$, those whose fathers had skilled occupations ( $p$-value $=$ 0.005 ), those of urban resident ( $p$-value $=0.000$ ), and those who watched TV everyday ( $p$-value $=0.030)$. Urban residence and age below 14 years were significantly associated with an earlier onset of menarche.

\footnotetext{
* Correspondence: christrah@yahoo.fr

${ }^{1}$ Surgical, Obstetrics, and Gynaecology unit, Kekem District Hospital, Kekem, West Region, Cameroon

2Department of Biochemistry, Faculty of Science, University of Dschang, Dschang, Cameroon

Full list of author information is available at the end of the article
}

(c) The Author(s). 2020 Open Access This article is licensed under a Creative Commons Attribution 4.0 International License, which permits use, sharing, adaptation, distribution and reproduction in any medium or format, as long as you give appropriate credit to the original author(s) and the source, provide a link to the Creative Commons licence, and indicate if changes were made. The images or other third party material in this article are included in the article's Creative Commons licence, unless indicated otherwise in a credit line to the material. If material is not included in the article's Creative Commons licence and your intended use is not permitted by statutory regulation or exceeds the permitted use, you will need to obtain permission directly from the copyright holder. To view a copy of this licence, visit http://creativecommons.org/licenses/by/4.0/ The Creative Commons Public Domain Dedication waiver (http://creativecommons.org/publicdomain/zero/1.0/) applies to the data made available in this article, unless otherwise stated in a credit line to the data. 


\begin{abstract}
(Continued from previous page)
Conclusion: Rural participants had better knowledge of puberty, menarche, and the menstrual cycle than their counterparts in the urban setting. The mean age at menarche over the last two decades has dropped by 7.4 and 4.2 months per decade in urban and rural Cameroon respectively. Mean age at menarche varies significantly with age group, urban/rural residence, state of both parents (both alive/at least one dead), occupation of the father, and frequency of watching TV. Age and urban/rural residence are associated with age at onset of menarche. The continually declining age at menarche is an alarm for future early menarche-linked morbidities.
\end{abstract}

Keywords: Age at menarche, Knowledge, Peri-menacheal, Comparative analysis, Cameroon, Young adolescent girls

\section{Background}

Menarche stands out amongst others as a crucial developmental stage in the lifespan of every normal young girl. It marks the onset of menstrual flow in the life of a developing young girl and comes with many fertility and reproductive implications. Though a commonly overlooked indicator in public health, menarche remains the key developmental marker of a girl's transition from childhood into adulthood [1, 2]. It is described as an essential indicator of the physical, nutritional, and reproductive health status of every developing young girl $[1,3]$. Puberty in young girls begins with thelarche (development of breast tissue), followed by pubarche (development of pubic hair), then menarche [4].

The mean age at menarche in Cameroon varies from urban to rural setting as was determined by Pasquet et al. using the "status quo" method in 1999 [3]. The study reported a mean age at menarche of $13.18 \pm 1.08$ years in the urban setting, $13.98 \pm 1.55$ years in the suburban setting, and $14.27 \pm 1.65$ years in the rural setting [3].

Over the last three decades, the age at menarche has experienced a consistent drop [2, 5]. Epidemiological evidence reveals multiple psychosocial and public health challenges that are due to the declining age of menarche. Early onset of menarche has been associated with early marriages [6,7], premature parenthood, breast cancer $[8,9]$, development of myoma [10], psychosocial disorders [11, 12], metabolic syndrome (diabetes, hypertension, and obesity) [13-16], short stature [17], preeclampsia [18], poor academic performance and substance abuse [2, 19]. A substantial body of evidence from developed and developing nations agrees that early menarche (generally defined as menarche before the age of 12 years) increases the likelihood of adverse sexual and reproductive health outcomes including early pregnancy and childbearing, sexually transmitted diseases, early sexual initiation, and sexual violence among adolescent girls $[1,2,20]$.

The age at menarche according to multiple epidemiological surveys has shown significant variations with economic status, educational attainment, race and ethnicity [21], place of residence (urban/rural) [3], nutritional status, and family sizes [2]. It is therefore a sensitive marker of many population indices including diet patterns, socio-economic status, geographical location, and environmental conditions.

Apart from the two studies by Pasquet et al. [3] and Monebenimp et al. [22] in 1999 on age at menarche, Studies on menarche and factors associated with menarche are still very few in Sub-Saharan Africa and particularly in Cameroon. The socio-economic and demographic changes over the years are likely to have been accompanied by changes in the age at onset of menarche. We therefore designed this study to update data on the current age at onset of menarche and to evaluate knowledge of young school girls on puberty, menarche and the menstrual cycle in a rural and urban setting in Cameroon, while doing a comparative analysis of the mean age at menarche across different groups.

\section{Methodology Study design}

A school-based cross-sectional study was conducted in two regions of Cameroon from February to March 2017 targeting young adolescent female students aged 9-16 years. Data collected from these young girls (in Yaoundé and Bamougoum) were going to help us update information on menarche in urban and rural Cameroon. This was done using a pretested auto-administered questionnaire and the collected data analysed using Epi-Info version 7.2.2.16.

\section{Setting}

The study was conducted in Yaoundé (urban) and Bamougoum (rural). Yaoundé is the administrative capital of Cameroon and is principally made up of the Mfoundi division (In the Centre Region of Cameroon). A cosmopolitan population characterises Yoaunde with about all the ethnic groups in Cameroon represented. Bamougoum on the other hand, is a rural area in Rural Bafoussam, Mifi division, West of Cameroon. The population is dominated by the Bamilekés (ethnic group) who are generally farmers and small traders with their closest urban centre being Bafoussam central town. 


\section{Sampling}

A multistep cluster sampling method was used in this study. Among the seven sub-divisions that make up the Mfoundi division, two were randomly selected for the survey (the names of the subdivisions were written on separate pieces of papers and folded, mixed and twoselected without replacement). All secondary schools in each of the two selected divisions were censored, their names written on separate pieces of papers, folded and mixed. One school was then selected randomly from each sub-division. The schools selected were Government Bilingual Practicing High School (GBPHS) Yaoundé and Government Bilingual High School (GBHS) Etoug-Ebe; Yaoundé. GBPHS and GBHS Yaoundé enrolled about 4800 and 6000 students respectively in the 2016/2017 academic year. As concerns the rural setting, due to the small number of schools, from the list of all secondary schools in Bamougoum, two were randomly selected. This was done by writing the names of all the schools on separate sheets of papers which were folded and mixed.. By this process, GBHS Bafoussam Rural and GBHS Nguache were selected. GBHS Bafoussam Rural and GBHS Nguache had an enrollment of 2500 and 3000 students respectively in the $2016 / 2017$ academic year.

At the level of the selected schools, given that our study targeted female students aged 9-16 years (adapted age range for the status quo method of evaluating the mean menarcheal age) who had experienced menarche [2], based on information from the school registers, Form three to lower sixth classes were included in the study in both urban and rural settings. All female students within this class range who were below 9 years or above 16 years of age or who had not yet experience menarche were not included. In each form or level, if multiple classes existed, one class was randomly selected and included in the study. In a selected classroom, all eligible participants who accepted to participate were enrolled in the study.

\section{Procedure of implementation and data collection}

When the protocol and data collection tools were ready, administrative authorisations were obtained from the selected schools and ethical clearance obtained from the institutional ethical review board of the University of Yaoundé I. The data collection tools were pretested in a sample of 15 students in a secondary school in Yaoundé (Faith Comprehensive Secondary School). A total of thirty (30) surveyors were recruited and trained on the consenting and data collection procedure in two training sessions of four hours each and then divided into six (6) teams each made up of five (5) members and headed by a team supervisor.
In each school, every selected class was assigned a team headed by a supervisor. Introduction and briefing on the topic of research was done by the supervisor of each team after which all eligible participants were given the information notice of the research to allow the students obtain written and signed consent of their parents/guardians back at home. All willing participants that had obtained the consent of their parents/guardians to participate were included in the survey after obtaining their verbal assent. The questionnaires were then submitted to each participant to fill with a clear notice of liberty to address questions to the research team members only. The participants were given as much time as they needed to complete the questionnaire, and all questions for clarification on the questionnaire answered. Data collected included; their Socio-demographic data, knowledge on puberty and menstruation, the onset of menstrual flow, and information on the age at menarche. During the submission of the filled questionnaire, the body weight (in $\mathrm{kg}$ ) of each participant was taken using a digital weighing scale and registered in the questionnaire. During weight measurement, each participant removed her shoes, and any other dress she wore on her uniform (only the school uniform, which is very light in our setting, was used during weight measurement). The height (in meters) of each respondent was then taken in an erect position using a graduated height measuring device (see the questionnaire: Supporting information S1).

\section{Data management and analysis}

All filled and submitted questionnaires were crosschecked for validity. Questionnaires that lacked vital information like the age of the participant and the age at menarche were excluded. Data were entered into a predesigned data entry sheet developed with the statistical software; Epi Info version 7.2.2.16. Proportions and their 95\% confidence intervals were presented for categorical variables (occupation, level of education, religion ... etc) while the mean or median was presented for continuous variables where applicable (age of the participant, age of menarche, and the number of household occupants ... .etc). A participant was classified to have good knowledge if she had a $50 \%$ correct score on the questions evaluating the level of knowledge on puberty, menarche, and menstruation. The age at menarche was scategorised into two groups based on the median age at menarche registered in the study.

With a statistically significant threshold set at $p$ value $=0.05$, and dependent on the result of the Bartlett's test for inequality of population variances, different means were compared using either the T-test or the Mann-Whitney/Wilcoxon Two-Sample Test (KruskalWallis test for two groups) where applicable. As concerns factors associated with menarche, the odds ratio 
and its 95\% confidence interval were used as a measure of the strength of association between age at menarche (dichotomously scategorised based on the median age at menarche) and selected covariates. All variables with a $p$-value less than 0.5 from the bivariate analysis were all controlled one for the others in the multiple logistic regression model with a statistically significant threshold set at $\mathrm{p}$-value $=0.05$.

\section{Ethical considerations}

Ethical approval for this study was obtained from the institutional ethical review board of the faculty of Medicine and Biomedical Sciences of the University of Yaoundé I. An information notice was given to each participant or their legal representatives. The written consent and verbal assent of the parent/guardian and participant respectively were obtained before data collection. Only willing and consenting participants were included in the survey. Confidentiality and the participant's autonomy were respected.

\section{Results}

Socio-demographic characteristics of the participants

Out of the 1230 young girls contacted for the study, 53 denied participating (consent denied by their parents), giving a non-response rate of $4.31 \%$. We excluded 20 questionnaires that were either wrongly filled or lacking vital information, and retained a total of 1157 participants (570 urban and 587 rural) for the study. The ages of the participants ranged from 10 to 16 years (No participant who was 9 years old was found to have started menstruation) with a median age of 15.0 years. The mean age of the participants was 15.1 years for rural dwellers and 14.8 years in urban dwellers. This age difference was statistically significant, with a $p$-value of 0.00 from unpaired t-test. Table 1 presents the sociodemographic characteristics of the participants. From Table 1, a majority of male parents of participants of the urban setting had attained higher education (52.98\%), whereas, in the rural setting, a majority of male parents ended at primary school (33.73\%). In the urban setting, most of the participants (54.21\%) had household members ranging from 1 to 5 whereas, in the rural setting, most of the participants (37.31\%) had household members above 10 . In the urban setting, $75.30 \%$ of male parents/guardians had skilled occupations whereas, in the rural setting, only $47.00 \%$ had skilled occupations. Out of 1157 participants, 1118(96.62\%) were Christians, and the rest were Muslims.

\section{Knowledge of participants on puberty, menarche, and menstruation}

Regarding the knowledge of our participants as a whole, $67.20 \%$ of rural participants had good knowledge concerning puberty, menarche, and the menstrual cycle, whereas only $46.00 \%$ had good knowledge in the urban setting. There existed a very statistically significant difference in the level of knowledge in urban and rural settings $(p$-value $<0.001)$. The knowledge of the participants on puberty and menarche is presented in Table 2 . From Tables 2, $91.40 \%$ and $92.80 \%$ of participants in urban and rural settings respectively had the correct definition of puberty. A Majority of participants $(80.58 \%$ in the rural and $63.00 \%$ in the urban setting) had the corect knowledge concerning the age of onset of menarche (reporting that menarche occurs between 9 and 16 years).

Table 3 summarises the knowledge of the participants on the menstrual cycle. It was noticed that $78.40 \%$ of the rural participants knew menses flow for 2 to 7 days as opposed to $86.70 \%$ in the urban setting. As concerns frequency of menstrual flow, $71.10 \%$ and $80.70 \%$ in the rural and urban setting respectively reported that menstrual flow occurs every 21 to 35 days.

The knowledge of the participants on the premenstrual signs and symptoms is shown in Table 4. In the urban setting, $66.50 \%$ identified menstrual cramps, $13.30 \%$ nausea and vomiting, $23.30 \%$ increased breast size, $8.10 \%$ fever, $15.40 \%$ dizziness as possible signs and

Table 1 Socio-demographic characteristics of the participants

\begin{tabular}{|c|c|c|c|c|c|c|c|}
\hline \multirow[t]{2}{*}{ Variable } & \multirow{2}{*}{$\begin{array}{l}\text { modalities/ } \\
\text { options }\end{array}$} & \multicolumn{2}{|c|}{ URBAN, $n=570$} & \multicolumn{2}{|c|}{ RURAL, $n=587$} & \multicolumn{2}{|c|}{ Total, $n=1157$} \\
\hline & & Frequency & Percentage & Frequency & Percentage & Frequency & Percentage \\
\hline \multirow{4}{*}{$\begin{array}{l}\text { Level of education } \\
\text { of male parent/guardian }\end{array}$} & never schooled & 17 & 2.98 & 103 & 17.55 & 120 & 10.37 \\
\hline & Primary & 77 & 13.51 & 198 & 33.73 & 275 & 23.77 \\
\hline & Secondary & 174 & 30.50 & 151 & 25.72 & 325 & 28.09 \\
\hline & Higher & 302 & 52.98 & 135 & 23.00 & 437 & 37.70 \\
\hline \multirow{3}{*}{$\begin{array}{l}\text { Number of household } \\
\text { Members }\end{array}$} & $1-5$ & 309 & 54.21 & 151 & 25.72 & 460 & 39.76 \\
\hline & $5-10$ & 214 & 37.54 & 177 & 30.15 & 391 & 33.79 \\
\hline & 10 and above & 47 & 8.24 & 219 & 37.31 & 266 & 22.99 \\
\hline \multirow{2}{*}{$\begin{array}{l}\text { Occupation of male } \\
\text { Parents }\end{array}$} & Skilled & 429 & 75.30 & 276 & 47.00 & 705 & 60.93 \\
\hline & Unskilled & 141 & 24.70 & 311 & 53.00 & 452 & 39.07 \\
\hline
\end{tabular}


Table 2 Knowledge of the participants on puberty and menarche

\begin{tabular}{|c|c|c|c|c|c|c|c|}
\hline \multirow[t]{2}{*}{ Questions } & \multirow[t]{2}{*}{ responses } & \multicolumn{2}{|c|}{ URBAN $n=570$} & \multicolumn{2}{|c|}{ RURAL $n=587$} & \multicolumn{2}{|c|}{ Total, $n=1157$} \\
\hline & & Frequency & $\begin{array}{l}\text { Percent } \\
\text { (\%) }\end{array}$ & Frequency & $\begin{array}{l}\text { Percent } \\
\text { (\%) }\end{array}$ & Frequency & $\begin{array}{l}\text { Percent } \\
(\%)\end{array}$ \\
\hline \multirow[t]{3}{*}{$\begin{array}{l}\text { What do you understand by } \\
\text { Puberty? }\end{array}$} & $\begin{array}{l}\text { Period of transition from childhood } \\
\text { to adulthood }\end{array}$ & 521 & 91.40 & 545 & 92.80 & 1066 & 92.13 \\
\hline & A period I can get pregnant & 39 & 6.80 & 35 & 6.00 & 74 & 6.40 \\
\hline & A time that I am fit for marriage & 10 & 1.80 & 7 & 1.20 & 17 & 1.47 \\
\hline \multirow{3}{*}{$\begin{array}{l}\text { At what age should a woman start } \\
\text { menstruating? }\end{array}$} & Less than 9 years & 159 & 27.89 & 107 & 18.20 & 266 & 22.99 \\
\hline & 9- 16 years & 360 & 63.16 & 473 & 80.60 & 833 & 71.99 \\
\hline & greater than 16 years & 51 & 8.94 & 7 & 1.20 & 58 & 5.01 \\
\hline
\end{tabular}

symptoms. In the rural setting, $72.10 \%$ identified menstrual cramps, $8.50 \%$ nausea and vomiting, $41.40 \%$ increased breast size, $10.60 \%$ fever, $11.40 \%$ dizziness.

Figure 1 summarises the sources of information of the participants on puberty, menarche, and the menstrual cycle (source of information on the horizontal axis and frequency on the vertical axis). Urban participants got information mostly from radio/TV 201(35.26\%) whereas, in the rural setting, the primary source of information was from school 300(51.10\%).

\section{Comparative analysis of age at menarche of the participant}

The prevalence of early menarche (menarche before 12 years) was 14.87 [12.92-17.02] \%. This prevalence was $16.32[13.51-19.57] \%$ and $13.29[10.78-16.27] \%$ in urban and rural setting, respectively. The mean age of the participants at menarche was $12.76 \pm 1.33$ years, with the mean age at menarche of $12.48 \pm 1.12$ years and $13.03 \pm$ 1.46 years, respectively in the urban and rural settings. This mean age at menarche was significantly higher in the rural participants compared with participants in the urban setting $(p$-value $<0.001)$. The median and the modal age of the participants at menarche was 13 years (Cut-off considered for analysis of factors associated with menarche).

Table 5 presents a comparative analysis of the mean age at menarche in different groups. The mean age at menarche was significantly lower in participants with both parents alive compared to those with at least one parent dead ( $p$-value $=0.0461)$. Participants with male parents who had skilled occupations attained menarche earlier compared to their counterparts with male parents having unskilled occupations $(p$-value $=0.005)$. Participants who watched television everyday attained menarche earlier compared to their counterparts who never watched television or did only on week-ends ( $\mathrm{p}$-value = 0.030). The mean age at menarche among participants with body mass index (BMI) greater than $25 \mathrm{~kg} / \mathrm{m}^{2}$ was significantly lower than that among participants with BMI lower than $25 \mathrm{~kg} / \mathrm{m}^{2}$ ( $p$-value $\left.=0.003\right)$. Participants in the urban setting attained menarche earlier than participants from the rural setting ( $p$-value $<0.001)$. Also, girls below 14 years attained menarche earlier compared to their older counterparts ( $p$-value $<0.001)$.

Table 6 presents factors associated with early onset of menarche among the participants both in simple and multiple logistic regression. On simple logistic regression, urban residence, age above 14 years, and BMI above $25 \mathrm{~kg} / \mathrm{m}^{2}$ were significantly associated with an early age at menarche. Participants from the urban setting were 1.76 times more likely to haveattained menarche earlier compared with those from the rural setting $(\mathrm{OR}=1.76[1.39-2.23], p$-value $=0.000)$. In the same light, participants aged above 14 years were significantly less likely to have attained menarche earlier

Table 3 Knowledge of the participants on the menstrual cycle

\begin{tabular}{|c|c|c|c|c|c|c|c|}
\hline \multirow[t]{2}{*}{ Questions } & \multirow[t]{2}{*}{ Responses } & \multicolumn{2}{|c|}{ RURAL $\mathrm{n}=587$} & \multicolumn{2}{|c|}{ URBAN $n=570$} & \multicolumn{2}{|c|}{ Total, $\mathrm{n}=1157$} \\
\hline & & Frequency & $\begin{array}{l}\text { Percent } \\
(\%)\end{array}$ & Frequency & $\begin{array}{l}\text { Percent } \\
(\%)\end{array}$ & Frequency & $\begin{array}{l}\text { Percent } \\
(\%)\end{array}$ \\
\hline \multirow{3}{*}{$\begin{array}{l}\text { For how many days should menses } \\
\text { flow? }\end{array}$} & Less than 2 days & 114 & 20.00 & 72 & 12.30 & 186 & 16.08 \\
\hline & 2 to 7 days & 447 & 78.40 & 509 & 86.70 & 956 & 82.63 \\
\hline & Greater than 7 days & 9 & 1.60 & 6 & 1.00 & 15 & 1.30 \\
\hline \multirow[t]{3}{*}{ How long is a menstrual cycle? } & Less than 21 days & 147 & 25.80 & 106 & 18.10 & 253 & 21.87 \\
\hline & 21 to 35 days & 405 & 71.10 & 474 & 80.70 & 879 & 75.97 \\
\hline & $\begin{array}{l}\text { Greater than } 35 \\
\text { days }\end{array}$ & 18 & 3.20 & 7 & 1.20 & 25 & 2.16 \\
\hline
\end{tabular}


Table 4 Knowledge of participants on the premenstrual signs and symptoms

\begin{tabular}{|c|c|c|c|c|c|c|}
\hline \multirow{2}{*}{$\begin{array}{l}\text { What are the } \\
\text { possible signs/ } \\
\text { symptoms that can } \\
\text { occur just before } \\
\text { menstruation? }\end{array}$} & \multicolumn{2}{|c|}{ URBAN, $n=570$} & \multicolumn{2}{|c|}{$R U R A L, n=587$} & \multicolumn{2}{|c|}{ Total, $n=1157$} \\
\hline & Frequency & Percent (\%) & Frequency & Percent (\%) & Frequency & Percent (\%) \\
\hline Menstrual cramps & 379 & 66.50 & 423 & 72.10 & 802 & 69.32 \\
\hline Nausea and vomiting & 76 & 13.30 & 50 & 8.50 & 126 & 10.89 \\
\hline Increased breast size & 133 & 23.30 & 243 & 41.40 & 376 & 32.50 \\
\hline Fever & 46 & 8.10 & 62 & 10.60 & 108 & 9.33 \\
\hline Dizziness & 88 & 15.40 & 67 & 11.40 & 155 & 13.40 \\
\hline
\end{tabular}

compared with those below 14 years $(\mathrm{OR}=0.33[0.25-$ $0.42], p$-value $=0.000)$. Participants with a body mass index greater than $25 \mathrm{~kg} / \mathrm{m}^{2}$ were significantly more likely to have an earlier menarche compared to those with a lower BMI $(\mathrm{OR}=1.72[1.07-2.77], p$-value $=0.024)$.

Upon control in a multiple logistic regression model, only age above 14 years and urban/rural residence remained statistically significant. The strength of association of the urban/rural setting with early menarche increased significantly. Participants from the urban setting were 4.35 times more likely to have attained menarche earlier compared with their counterparts in the rural setting $(\mathrm{OR}=4.35[2.27-8.33]$, $\mathrm{p}$-value $=0.000)$. In the same light, participants aged above 14 were 0.30 times less likely to have attained menarche earlier compared with their younger counterparts.

\section{Discussion}

Menarche is a physiological event occurring during the development of every normal young girl. This study updates data on menarche in a rural and urban Cameroonian setting, goes further to evaluate the knowledge of young adolescent girls on puberty, menarche, and the menstrual cycle while identifying possible factors influencing the age of onset of menstrual flow in these girls.
Regarding the knowledge of our participants, $56.6 \%$ of participants had above $50 \%$ of the score (good knowledge) concerning puberty, age at menarche, and menstrual cycle. This finding is similar to that obtained in a Ghanaian study in 2016, which reported an average knowledge of $57 \%$ on menarche and the menstrual cycle [23]. The proportion of participants with good knowledge is unsurprisingly higher in this study, given that the target population was university students. Up to $67.20 \%$ of participants from rural settings had good knowledge, whereas only $46.00 \%$ had good knowledge in the urban setting. This difference may be because the primary source of information in the rural area was the school $(51.10 \%)$ whereas in the urban participants it was the radio/TV and friends. The higher proportion of rural participants with good knowledge in our study questions the influence of the information source types on the knowledge of the participants. Probably, participants in the rural zone who have the school as their primary source of information were not influenced by diverse ideas in this field. Also, the quality of teaching care administered in the subject matter in both settings might be different. Our study however did not evaluate the quality of education administered to students in this domain, and therefore we cannot be conclusive in our reasoning.

\section{SOURCES OF IMFORMATION}

mURBAN $=$ RURAL

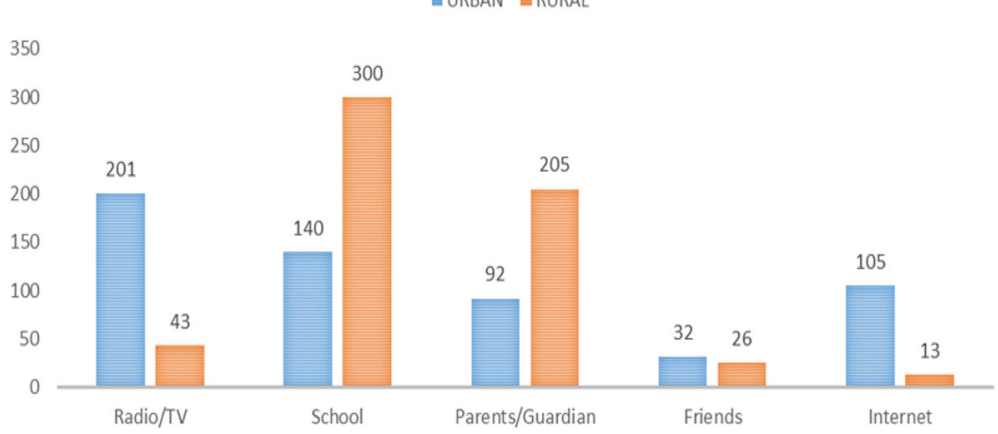

Fig. 1 Sources of information of the participants on puberty, menarche and the menstrual cycle 
Table 5 Comparative analysis of the mean age at menarche stratified by some variables

\begin{tabular}{|c|c|c|c|c|}
\hline Variables & Modality & Mean age (year) & SD (standard deviation) & $p$-value \\
\hline \multirow[t]{2}{*}{ State of parents } & Both alive & 12.72 & 1.36 & $0.0461^{*, \mu}$ \\
\hline & At least one dead & 12.95 & 1.32 & \\
\hline \multirow[t]{2}{*}{ Age above 14 year } & Yes & 13.02 & 1.39 & $0.000^{£, \mu}$ \\
\hline & No & 12.25 & 1.03 & \\
\hline \multirow[t]{2}{*}{ Occupation of male parents } & Skilled & 12.67 & 1.27 & $0.005^{£, \mu}$ \\
\hline & Unskilled & 12.90 & 1.41 & \\
\hline \multirow[t]{2}{*}{ Male Parents' level of education } & Not schooled and primary & 12.89 & 1.34 & $0.100^{*}$ \\
\hline & Above primary & 12.73 & 1.33 & \\
\hline \multirow[t]{2}{*}{ Watching of Television } & Never or only on week-ends & 12.86 & 1.34 & $0.030^{*, \mu}$ \\
\hline & Everyday & 12.69 & 1.32 & \\
\hline \multirow[t]{2}{*}{$B M I$} & Greater than $25 \mathrm{~kg} / \mathrm{m}^{2}$ & 12.48 & 1.14 & $0.003^{£, \mu}$ \\
\hline & Less than $25 \mathrm{~kg} / \mathrm{m}^{2}$ & 12.94 & 1.46 & \\
\hline \multirow[t]{2}{*}{ Religion } & Christian & 12.76 & 1.33 & $0.711^{*}$ \\
\hline & Muslim/others & 12.83 & 1.41 & \\
\hline \multirow[t]{2}{*}{ Urban/Rural resident } & Urban & 12.48 & 1.12 & $0.000^{£, \mu}$ \\
\hline & Rural & 13.03 & 1.46 & \\
\hline
\end{tabular}

${ }^{£}$ Mann-Whitney/Wilcoxon Two-Sample Test $p$-value, ${ }^{*}$ t-Test $p$-value, ${ }^{\mu}$ Statistically significant $p$-value $<0.05$

Moreover, the mean age of participants was 15.1 years for rural dwellers and 14.8 years in urban dwellers. This age difference was statistically significant, with a $p$-value of 0.00 from unpaired t-test. Older girls have a higher propensity of being exposed to information on puberty and menstruation through parents' education, studies in school, peer discussion, and other media. This might be a possible explanation of why rural-dwelling girls had better knowledge of puberty and menstruation than the urban-dwelling girls. Also, it is possible that our results might report a relatively lower level of knowledge given the nature of the designed questionnaire, the conditions under which the questionnaire was administered, and the age group considered.
The primary source of information on puberty, menarche, and menstrual cycle in the urban participants was the radio/TV (35.26\%) whereas, in the rural area, the primary source of information was the school (51.10\%). This is expected, given that the urban areas are generally associated with easy access to audiovisual signals. When we look at the proportion of students with good knowledge in rural and urban settings, we can state that the level of knowledge is still relatively low and even lower in the urban setting. Good knowledge has been associated with better attitudes and good attitudes with practices. This level of knowledge among already menstruating girls could be associated with poor practices as far as sexual behaviour and menstrual hygiene are

Table 6 Factors associated with age at menarche (Before 13 years)

\begin{tabular}{|c|c|c|c|c|c|c|}
\hline \multirow[t]{2}{*}{ Factors } & \multicolumn{3}{|c|}{ Bivariate analysis } & \multicolumn{3}{|c|}{ Multivariate analysis } \\
\hline & OR & $\mathrm{Cl} 95 \%$ & p-value & Adj OR & Adj Cl 95\% & $p$-value \\
\hline Resident (urban/rural) & 1.76 & $1.39-2.23$ & $0.000^{*, \mu}$ & 4.35 & $2.27-8.33$ & $0,000^{\mu}$ \\
\hline Level of education of male parent above primary $(\mathrm{Y} / \mathrm{N})$ & 1.12 & $0.83-1.52$ & $0.449^{*}$ & 0.10 & $0.49-2.01$ & 0.997 \\
\hline Age above 14 years $(\mathrm{Y} / \mathrm{N})$ & 0.33 & $0.25-0.42$ & $0.000^{*, \mu}$ & 0.30 & $0.17-1.52$ & $0.000^{\mu}$ \\
\hline Occupation of male parent (Unskilled/skilled) & 0.80 & $0.62-1.01$ & $0.066^{*}$ & 1.38 & $0.74-2.58$ & 0.312 \\
\hline Christian (Y/N) & 1.06 & $0.57-1.98$ & 0.857 & & & \\
\hline Always eats to satisfaction (Y/N) & 1.10 & $0.82-1.48$ & 0.511 & & & \\
\hline Both parents alive $(\mathrm{Y} / \mathrm{N})$ & 1.28 & $0.91-1.80$ & $0.162^{*}$ & 0.48 & $0.22-1.05$ & 0.066 \\
\hline Watches TV everyday & 1.16 & $0.91-1.47$ & $0.221^{*}$ & 1.49 & $0.87-2.53$ & 0.143 \\
\hline BMI above $25 \mathrm{Kg} / \mathrm{m}^{2}$ & 1.72 & $1.07-2.77$ & $0.024^{*, \mu}$ & 0.98 & $0.56-1.70$ & 0.939 \\
\hline
\end{tabular}

* Variables included in the multiple logistic regression model ( $p$-value $<0.5),{ }^{\mu}$ Statistically significant $p$-value $<0.05$ 
concerned. Readapting or strengthening the course content of these young adolescent girls in their respective schools is indispensable in improving the quality of knowledge of these young girls. Parental home counselling and sensitisation of the young girl is also of utmost importance.

The mean age at menarche in our study was $12.76 \pm$ 1.33 years, with a mean age at menarche in the urban setting (Yaoundé) of $12.48 \pm 1.12$ years and the rural setting (Bamougoum) of $13.03 \pm 1.46$ years. When compared, this difference was statistically significant, with a $p$-value of less than 0.001. A study carried out in Cameroon in 1999 by Pasquet et al. reported an average age at menarche of $13.18 \pm 1.08$ years in urban, $13.98 \pm 1.55$ years in the suburban area, and $14.27 \pm 1.65$ years in the rural area [3] The trend is similar to the trend recorded in this study, given that the age at menarche decreased from rural, through suburban to the urban setting. Compared to the results of Pasquet et al. the mean age at menarche has dropped by 1.24 years and 0.7 years in the urban and rural settings respectively over the last two decades in Cameroon. This drop of the mean age at menarche corresponds to a decrease of 7.4 and 4.2 months every decade in the urban and rural setting respectively. We are however not very conclusive about this decrease as these surveys were carried out among participants with different age limits. This declining trend of the age at menarche has also been reported in population studies carried out in Gambia [24], China [25], and Vietnam [26]. All the abovecited literature presented significant differences between the ages of menarche in urban and rural settings.

This declining trend of the age at menarche is in line with the high prevalence of early menarche recorded in this survey. According to our findings, $14.87 \%$ of these young girls attained menarche before the age of 12 years. This progressively early onset of menarche has been described to be associated with the development of multiple gynaecological morbidities like the development of myoma [10], cardiovascular disease [15, 27], metabolic syndrome [14], type 2 diabetes [16], preeclampsia [18], and various forms of cancer $[8,9]$.

Comparative analysis of the mean age at menarche across different groups showed that the mean age at menarche was significantly influenced by the state of both parents (both alive/ at least one dead), the current age of the participants, the occupation of the parents, frequency of watching television, and body mass index of the participants. With both parents alive, the standard of living of the young girl is likely to be better given the increased likelihood of a better socio-economic status [2]. According to a study on age at menarche and socio-economic status in Poland, girls from families with high socio-economic status experienced menarche at an earlier age than girls from families with lower socio-economic status [28]. Also, multiple studies have agreed that higher BMI is associated with an increased likelihood of early menarche [29-31]. Watching television has been described to have a significant influence on the sexual development and behaviour of adolescent girls. It has also been associated with an increased likelihood of early menarche [32, 33]. Participants with parents having skilled occupations are generally more likely to experience an earlier menarche compared to those whose parents have unskilled occupations. This left us hypothesising that participants with parents having skilled occupations were more likely to have a better socio-economic state compared to others. This could be a plausible explanation for the difference. Studies have however presented contrasting findings; stating that the age at menarche did not depend on the parent's occupation [2].

When we evaluated by logistic regression with age at menarche categorised (Menarche before 13 years), we found that only age and urban/rural residence were significantly associated with age at menarche. As already discussed above, urbanisation is by far the strongest factor associated with menarche among young girls. Girls in the urban setting were more than four times more likely to experience menarche earlier compared to their counterparts in rural settings even upon control for multiple variables. The growing urbanisation of the different rural zones in Cameroon is likely to be associated with a very significant drop in the age of first menstrual flow in Cameroon. This will mean higher exposure to early menarche-linked morbidities in the future. Older girls reported a significantly higher mean age at menarche compared to their younger counterparts. Logistic regression results confirmed age as a statistically significant factor associated with age at menarche. The impact of rapid urbanisation over the years and the rapid changes in the methods of child upbringing associated with an increasing prevalence of childhood obesity could explain this [34].

The level of education of the male parent and BMI were significant factors only on simple logistic regression. These factors have already been reported to be associated with menarche in multiple studies [2, 30, 31]. These two factors are possible confounders of the urban/rural residence, given that parents in the urban setting are likely to be more educated than their counterparts in the rural setting. Also, city dwellers end up with a significantly larger BMI compared to those in rural settings [35].

The data herein should be interpreted with care. Information bias was likely to affect our results given that we conducted the study on already menstruating females. The data given to us was therefore retrospective and could be subjected to errors (failure of memory). Moreover, the participants could lie given that some of the questions were personal and did explore their reproductive development. The data collected in this survey does 
not permit us to evaluate all possible factors associated with earlier onset of menarche. Other possible factors like level of education and occupation of the mother, the wealth index of the family, and nutritional status were not evaluated in this study. Also, the cross-sectional design of the study does not permit us to establish cause-effect relations between variables. The findings in this research are not representative of all urban and rural zones in Cameroon; more extensive studies representing all the rural and urban zones in Cameroon are necessary. In addition, the difference observed between the urban and rural population in this study could be bigger given that the population of city dwellers is generally cosmopolitan (case of Yaoundé) compared to the case of Bamougoum (dominated principally by the Bamilekés; the major ethnic group of the West Region of Cameroon).

\section{Conclusion}

Even though young girls in Bamoungoum (rural setting) have better knowledge of puberty, menarche, and the menstrual cycle, the overall level of knowledge in both settings is relatively good. The mean age at menarche of menstruating girls aged 9-16 years is $12.76 \pm 1.33$ years, with a mean age at menarche of $12.48 \pm 1.12$ years and $13.03 \pm 1.46$ years respectively in the urban and rural settings. The mean age at menarche over the last two decades in Cameroon has dropped by 7.4 and 4.2 months in the urban and rural settings respectively. The mean age at menarche depends on some factors like urban/ rural residence, state of the parents (both alive/ at least one dead), the occupation of the male parent, age group, frequency of watching TV, and body mass index. Upon control for confounders, urban residence and age below 14 years were significantly associated with earlier onset of menarche.

Parental home counselling and sensitisation, associated with focused reinforcement of their course content on puberty, menarche, and the menstrual cycle is indispensable in stepping up the knowledge of these young girls. Declining age at menarche serves as an essential indicator of the future burden of gynaecological, and cardiometabolic, morbi-mortality.

\section{Supplementary Information}

The online version contains supplementary material available at https://doi. org/10.1186/s12889-020-09787-y.

Additional file 1: Supporting information file (S1). Questionnaire on menarche.

Additional file 2: Supporting information file (S2). Database containing "status quo" data on the age of menarche in rural and urban Cameroon.

\section{Abbreviations}

AOR: Adjusted Odds Ratio; BMl: Body Mass Index; Cl: Confidence Interval; GBPHS: Government Bilingual Practicing High School; GBHS: Government Bilingual High School; OR: Odds Ratio

\section{Acknowledgements}

Our sincere gratitude goes to all the young girls and their parents who accepted to participate in the study.

\section{Authors' contributions \\ ABA NNT and BK conceived the study and guided field data collection; ABA and MNY analysed the data; ABA drafted the manuscript; ISA, NNT, and MNY contributed to supervising data collection and revising the manuscript. All authors read and approved the final manuscript.}

\section{Funding}

No funding was obtained for this research.

\section{Availability of data and materials}

The datasets used and/or analysed during the current study are available in the database submitted as supporting information (S2).

\section{Ethics approval and consent to participate}

Ethical approval for this study was obtained from the institutional ethical review board of the faculty of Medicine and Biomedical Sciences of the University of Yaoundé I. An information notice was given to each participant or their legal representatives. The written consent and verbal assent of the parent/guardian and participant respectively was obtained before data collection. Only willing and consenting participants were included in the survey. Confidentiality and the participant's autonomy were respected.

\section{Consent for publication}

Not applicable.

\section{Competing interests}

The authors declare that they have no competing interests.

\section{Author details}

'Surgical, Obstetrics, and Gynaecology unit, Kekem District Hospital, Kekem, West Region, Cameroon. 'Department of Biochemistry, Faculty of Science, University of Dschang, Dschang, Cameroon. ${ }^{3}$ Obstetrics and Gynaecology unit, Baham District Hospital, Baham, West Region, Cameroon. ${ }^{4}$ Medecins Sans Frontieres-Spain (MSF-OCBA), Epidemiology and Public Health, Old International Primary School Line NTA/Circular Road Junction Road by Dambua Road, Maiduguri, Nigeria. Internal Medicine unit, Bafoussam Regional Hospital, Bafoussam, West Region, Cameroon. ${ }^{6}$ Dschang District Hospital, Dschang, West Region, Cameroon. 'Department of Obstetrics/ Gynaecology and Maternal Health, Faculty of Medicine and Pharmaceutical Sciences, University of Dschang, Dschang, West Region, Cameroon.

Received: 17 January 2020 Accepted: 28 October 2020

Published online: 04 November 2020

\section{References}

1. Ibitoye M, Choi C, Tai H, Lee G, Sommer M. Early menarche : a systematic review of its effect on sexual and reproductive health in low- and early menarche : a systematic review of its effect on sexual and reproductive health in low- and middle-income countries. PLoS One. 2017;12(6):1-24. Available from:. https://doi.org/10.1371/journal.pone.0178884.

2. Karapanou O, Papadimitriou A. Determinants of menarche. Reprod Biol Endocrinol. 2010;8(115):1-8.

3. Pasquet P, Rikong-Adie H, Befidi-Mengue R, Garba M, Froment A. Age at menarche and surbanisation in Cameroon : current status and secular trends. Ann Hum Biol. 1999;26(1):89-97.

4. Reis M, Reis M, Ramiro L, Godeau E, De Matos MG. Age at menarche in Portuguese adolescent sectional study with HBSC Portuguese survey age at menarche in Portuguese adolescents adolescent - a crosssectional study with HBSC Portuguese survey. Glob Adv Res J Educ Res Rev. 2016;5(4):55-62.

5. Ganabathy NA, Widjajakusuma A, Hidayat D. Age Pattern at Menarche as Results from a Puberty Survey. Althea Med J. 2016;3(December):640-3. 
6. Field E, Ambrus A. Early marriage, age of menarche, and female schooling attainment in Bangladesh. J Polit Econ. 2008;1 16(5):881-91.

7. Belsky J, Steinberg L, Houts RM, Halpern-Felsher BL. The NICHD early child care research network. The development of reproductive strategy in females: early maternal harshness $\rightarrow$ earlier menarche $\rightarrow$ increased sexual risk taking. Dev Psychol. 2010;46(1):120-8.

8. Hsieh C-C, Trichopoulos D, Katsouyanni K, Yuasa S. Age at menarche, age at menopause, height and obesity as risk factors for breast cancer: associations and interactions in an international case-control study. Int J Cancer. 1990; 45(5):796-800.

9. Hamajima N, Hirose K, Tajima K, Rohan T, Friedenreich CM, Calle EE, et al. Menarche, menopause, and breast cancer risk: individual participant metaanalysis, including 118964 women with breast cancer from 117 epidemiological studies. Lancet Oncol. 2012;13(11):1141-51.

10. Edwards DRV, Baird DD, Hartmann KE. Association of age at menarche with increasing number of fibroids in a cohort of women who underwent sstandardised ultrasound assessment. Am J Epidemiol. 2013;178(3):426-33.

11. Alcalá-Herrera V, Marván ML. Early menarche, depressive symptoms, and coping strategies. J Adolesc. 2014;37(6):905-13.

12. Jean RT, Wilkinson AV, Spitz MR, Prokhorov A, Bondy M, Forman MR. Psychosocial risk and correlates of early menarche in Mexican-American girls. Am J Epidemiol. 2011;173(10):1203-10.

13. Dreyfus J, Jacobs DR, Mueller N, Schreiner PJ, Moran A, Carnethon MR, et al. Age at Menarche and Cardiometabolic Risk in Adulthood: The Coronary Artery Risk Development in Young Adults Study. J Pediatr. 2015;167(2):344-352.e1.

14. Stöckl D, Meisinger C, Peters A, Thorand B, Huth C, Heier M, et al. Age at menarche and its association with the metabolic syndrome and its components: results from the Kora F4 study. PLoS One. 2011;6(10):1-7.

15. Remsberg KE, Demerath EW, Schubert CM, Chumlea WC, Sun SS, Siervoge RM. Early menarche and the development of cardiovascular disease risk factors in adolescent girls: the Fels longitudinal study. J Clin Endocrinol Metab. 2005;90(5):2718-24.

16. Lim SW, Ahn JH, Lee JA, Kim DH, Seo JH, Lim JS. Early menarche is associated with metabolic syndrome and insulin resistance in premenopausal Korean women. Eur J Pediatr. 2016;175(1):97-104.

17. Helle S. A tradeoff between reproduction and growth in contemporary Finnish women. Evol Hum Behav. 2008:29(3):189-95.

18. Abetew DF, Enquobahrie DA, Dishi M, Rudra CB, Miller RS, Williams MA. Age at menarche, menstrual characteristics, and risk of preeclampsia. ISRN Obstet Gynecol. 2011;2011:1-6.

19. Goon DT, Toriola AL, Uever J, Wuam S, Toriola OM. Growth status and menarcheal age among adolescent school girls in Wannune, Benue Growth status and menarcheal age among adolescent school girls in Wannune, Benue State, Nigeria. BMC Pediatr. 2010;10(16):1-6.

20. Glynn JR, Kayuni N, Floyd S, Banda E, Francis-Chizororo M, Tanton C, et al. Age at menarche, schooling, and sexual debut in northern Malawi. PLoS One. 2010;5(12):1-8.

21. Chumlea WC, Schubert CM, Roche AF, Kulin HE, Lee PA, Himes JH, et al. Age at menarche and racial comparisons in US girls. Pediatrics 2003;111(1):110-113.

22. Monebenimp F, Kagho JM, Ekoe BT, Mve KV, Lantum DN. Menarche and adolescent sexuality in schools in Yaounde, Cameroon. Clin Mother Child Heal. 2007:4(1):659-64.

23. Ameade EPK, Garti HA. Relationship between Female University students' knowledge on menstruation and their menstrual hygiene practices: a study in tamale. Ghana Adv Prev Med. 2016:2016:1-10.

24. Prentice S, Fulford AJ, Jarjou LMA, Goldberg GR, Prentice A. Evidence for a downward secular trend in age of menarche in a rural Gambian population. Ann Hum Biol. 2010;35(5):717-21.

25. Graham MJ, Larsen $U, X u X$. Secular trend in age at menarche in China: a case study of two rural counties in Anhui Province. J Biosoc Sci. 1999;31(2): 257-67.

26. Kim SH, Lee S-E, Lyu J-E, Hwang J-Y, Chung H-W, Kim W-Y. Secular trend in age at menarche for Vietnamese marriage immigrants in Korea born between 1960 and 1989. FASEB J. 2009;23(S1):551.10-551.10. https://doi.org/ 10.1096/fasebj.23.1_supplement.551.10.

27. Survey NE. Association Between Age at Menarche and Risk Factors for Cardiovascular Diseases in Korean Women. Medicine (Baltimore). 2016; 95(18):1-7.
28. Wronka I, Pawlińska-Chmara R. Menarcheal age and socio-economic factors in Poland. Ann Hum Biol. 2005;32(5):630-8.

29. Ong KK, Northstone K, Wells JCK, Rubin C, Ness AR, Golding J, et al. Earlier mother's age at menarche predicts rapid infancy growth and childhood obesity. PLoS Med. 2007;4(4):737-42.

30. Jansen EC, Herrán OF, Villamor E. Trends and correlates of age at menarche in Colombia: results from a nationally representative survey. Econ Hum Biol. 2015;19:138-44.

31. Oh CM, Oh IH, Choi KS, Choe BK, Yoon TY, Choi JM. Relationship between body mass index and early menarche of adolescent girls in Seoul. J Prev Med Public Heal. 2012:45(5):227-34.

32. Trentham-Dietz A, Nichols HB, Remington PL, Yanke L, Hampton JM, Newcomb PA, et al. Correlates of age at menarche among sixth grade students in Wisconsin. Wis Med J. 2005;104(7):65-9.

33. Chavarro JE, Peterson KE, Sobol AM, Wiecha JL, Gortmaker SL. Effects of a school-based obesity-prevention intervention on menarche (United States). Cancer Causes Control. 2005;16(10):1245-52.

34. Mumby HS, Elks CE, Li S, Sharp SJ, Khaw KT, Luben RN, et al. Mendelian randomisation study of childhood BMI and early menarche. J Obes. 2011; 2011:1-6.

35. Delisle H, Ntandou-Bouzitou G, Agueh V, Sodjinou R, Fayomi B. Urbanisation, nutrition transition and cardiometabolic risk: the Benin study. Br J Nutr. 2012;107(10):1534-44

\section{Publisher's Note}

Springer Nature remains neutral with regard to jurisdictional claims in published maps and institutional affiliations.
Ready to submit your research? Choose BMC and benefit from:

- fast, convenient online submission

- thorough peer review by experienced researchers in your field

- rapid publication on acceptance

- support for research data, including large and complex data types

- gold Open Access which fosters wider collaboration and increased citations

- maximum visibility for your research: over $100 \mathrm{M}$ website views per year

At BMC, research is always in progress.

Learn more biomedcentral.com/submissions 